\title{
Bx open Ten years of asthma admissions to adult
critical care units in England and Wales
}

Ben Gibbison, ${ }^{1}$ Kathryn Griggs, ${ }^{2}$ Mome Mukherjee, ${ }^{3}$ Aziz Sheikh ${ }^{3}$

To cite: Gibbison B, Griggs K, Mukherjee $\mathrm{M}$, et al. Ten years of asthma admissions to adult critical care units in England and Wales. BMJ Open 2013;3: e003420. doi:10.1136/ bmjopen-2013-003420

- Prepublication history for this paper is available online. To view these files please visit the journal online (http://dx.doi.org/10.1136/ bmjopen-2013-003420).

Received 15 June 2013 Revised 26 July 2013 Accepted 15 August 2013

${ }^{1}$ Department of Anaesthesia, University Hospitals Bristol NHS FT, Bristol, UK

${ }^{2}$ Intensive Care National Audit and Research Centre, London, UK

${ }^{3}$ Allergy and Respiratory Research Group, Centre for Population Health Sciences. The University of Edinburgh, Edinburgh, UK

Correspondence to Dr Ben Gibbison; mdbjjg@bris.ac.uk

\section{ABSTRACT}

Objectives: To describe the patient demographics, outcomes and trends of admissions with acute severe asthma admitted to adult critical care units in England and Wales.

Design: 10-year, retrospective analysis of a national audit database.

Setting: Secondary care: adult, general critical care units in the UK.

Participants: 830808 admissions to adult, general critical care units.

Primary and secondary outcome measures:

Demographic data including age and sex, whether the patient was invasively ventilated or not, length of stay (LOS; both in the critical care unit and acute hospital), survival (both critical care unit and acute hospital) and time trends across the 10-year period.

Results: Over the 10-year period, there were 11948 ( $1.4 \%$ of total) admissions with asthma to adult critical care units in England and Wales. Among them 67.5\% were female and $32.5 \%$ were male (RR F:M 2.1; 95\% $\mathrm{Cl} 2.0$ to 2.1). Median LOS in the critical care unit was 1.8 days (IQR 0.9-3.8). Median LOS in the acute hospital was 7 days (IQR 4-14). Critical care unit survival rate was $95.5 \%$. Survival at discharge from hospital was $93.3 \%$. There was an increase in admissions to adult critical care units by an average of $4.7 \%(95 \% \mathrm{Cl} 2.8$ to 6.7$) /$ year.

Conclusions: Acute asthma represents a modest burden of work for adult critical care units in England and Wales. Demographic patterns for admission to critical care unit mirror those of severe asthma in the general adult community. The number of critical care admissions with asthma are rising, although we were unable to discern whether this represents a true increase in the incidence of acute asthma or asthma severity.

\section{INTRODUCTION}

Asthma is one of the most common chronic diseases in the western world and is responsible for a considerable amount of public spending. The UK estimates suggest that asthma costs at least $£ 750$ million/ $/$ year $^{1}$ in direct cost to the National Health Service (NHS), although it is widely accepted that the societal costs are likely to be much

\section{ARTICLE SUMMARY}

Strengths and limitations of this study

- This is the largest study of acute asthma admissions to adult critical care units so far.

- The data are drawn from a large, national audit and are well validated. The number of 'missed' cases is likely to be small.

- The cross-over between chronic bronchitis, chronic obstructive pulmonary disease, pneumonia in an asthmatic and 'diagnostically correct' asthma make epidemiological assessment difficult.

higher. Estimates also suggest that about 35$50 \%$ of overall spending on asthma is for acute exacerbations ${ }^{2}$ and that around threequarters of these episodes represent treatment 'failure'. ${ }^{3}$ Treatment in a critical care unit represents those most severely affected and is the endpoint for those who have not been adequately controlled by prevention and intervention at earlier stages in their care pathway.

There is no strict definition for what constitutes a 'critical care unit', and indeed the definition varies from country to country. ${ }^{4}$ There are fewer critical care beds per capita in the UK than countries such as the USA and Germany and thus patients admitted to the UK critical care units are more severely ill and have a higher mortality than other countries in Western Europe and the USA. ${ }^{5}$

The epidemiology of asthma in paediatric critical care units has been extensively studied. $^{6-9}$ There are in comparison few large, long-term studies of the epidemiology of adult asthma admissions to critical care units (see table 1). The aim of this study was to examine the demographics, outcomes and trends of acute asthma admissions in adult critical care units throughout England and Wales between 2002 and 2011.

\section{METHODS}

The Intensive Care National Audit and Research Centre Case Mix Programme (ICNARC CMP) database is a national 


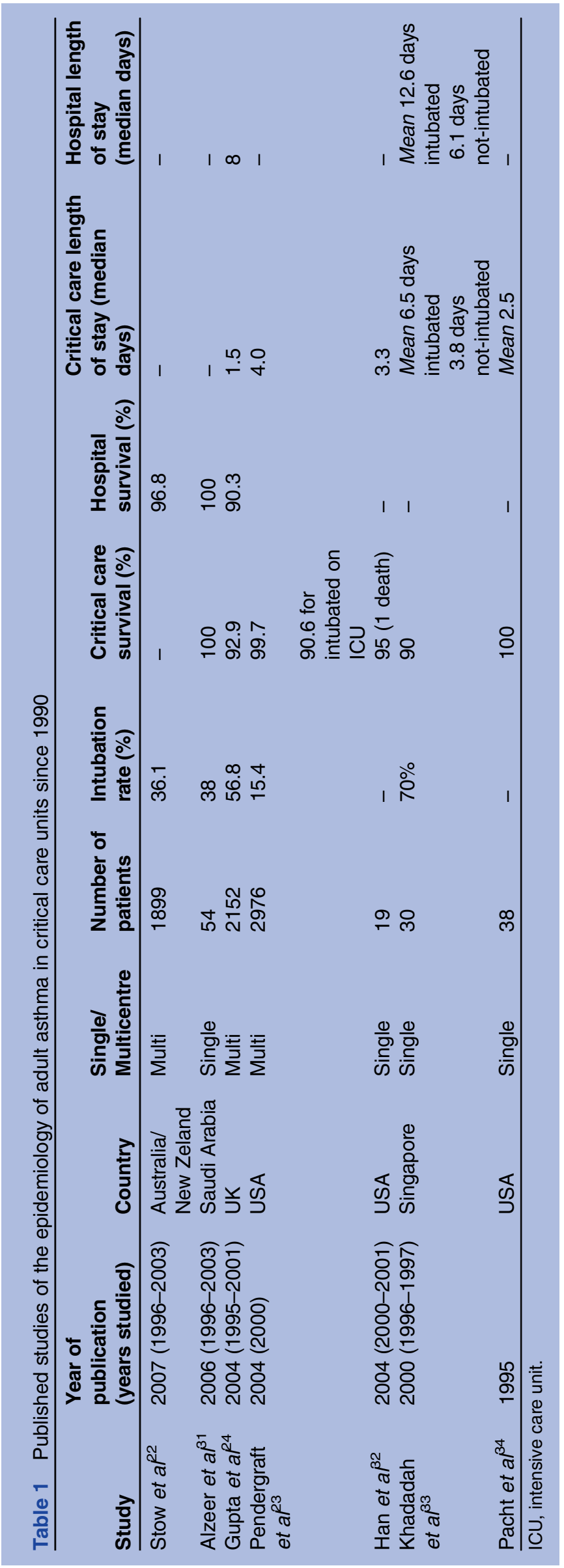

comparative audit of adult, general critical care units spread geographically across England, Wales and Northern Ireland. The ICNARC currently covers around $60-70 \%$ of the UK NHS adult, general critical care units. Only data from England and Wales were included in this analysis.

The ICNARC CMP data are recorded prospectively on standard forms by trained data collectors according to clearly agreed definitions and rules. Abstraction is usually retrospective and based on chart review. Data are validated both locally and nationally for completeness, inconsistencies and illogical data and this process is repeated until all queries are dealt with. Data are then incorporated into the CMP. The ICNARC coding method is a five-tiered hierarchical method specifically designed by ICANARC for coding admissions to critical care. The code builds by type of condition (medical or surgical), body system, body site, body process and specific condition. ${ }^{10}$

Admissions were identified as having acute asthma if the primary or secondary reason for admission was coded as an 'asthma attack in new or known asthmatic'.

Demographic data, along with whether or not the patient was invasively ventilated and outcomes, in terms of length of critical care unit stay and death was collected.

Although data from some patients aged under 15 years were included in our dataset, not all admissions to paediatric acute asthma from England and Wales were captured. The UK model of care means that paediatric critical care is provided by dedicated, regional critical care units, which do not submit data to the ICNARC CMP. Some short-term care and stabilisation of children sometimes occurs in general critical care units before moving children to regional paediatric units, hence some children's data were included in the ICNARC CMP.

\section{Invasive ventilation}

A patient was regarded as being ventilated in the first $24 \mathrm{~h}$ on the basis of a 'ventilated respiratory rate' being recorded in the patient record.

\section{Length of stay}

Length of stay (LOS) was collected in days and fractions of days using the dates and times of critical care unit admission and discharge. Admission and ultimate discharge dates and times from an acute hospital were used for acute hospital LOS.

\section{Deaths}

Critical care unit and acute hospital mortality data were collected. Critical care unit mortality was defined if the status at discharge from the critical care unit was dead. Acute hospital mortality was defined if the status at ultimate discharge from acute hospital was dead.

Descriptive and statistical analyses were undertaken using STATA V.10.1 (StataCorp LP, Texas, USA), PASW Statistics V.18 (IBM Ltd, Feltham, UK) and Excel (Microsoft Corp. Redmond, Washington, USA). Rate ratios (RR) and 95\% CIs were calculated for sex 
differences using the methods described by Armitage and Berry. ${ }^{11}$ Linear regression was performed on logtransformed number of admissions in each year using SPSS V.19(IBM Ltd, Feltham, UK) to establish trends in admissions over time, taking 2002 as the base year. Owing to the low number of admissions in 2002, logarithmic transformation allowed stabilisation of admission rates.

\section{RESULTS}

The number of participating units in the ICNARC CMP rose from 142 to 205 units across the time period.

During the period 2002 to 2011, there were 830808 admissions to adult general critical care units included in the ICNARC CMP. Of these admissions 11948 (1.4\%) had a diagnosis of acute asthma, $67.5 \%$ (8 064) of those with acute asthma were women and $32.5 \%$ (3 884) were men (RR F:M $2.195 \%$ CI 2.0 to 2.1). The demographics of the study population are shown in table 2 .

Within the first $24 \mathrm{~h} 46.2 \%$ (5 519) of admissions were invasively ventilated.

The median LOS in the critical care unit was 1.8 days (IQR 0.9-3.8). Median length of hospital stay was 7 days (IQR 4-14).

Overall survival on critical care unit was 95.5\% (539 deaths). Survival to acute hospital discharge was 93.3\% (763 deaths). Mortality by age and sex are shown in table 3 .

Total admissions with acute asthma by year are shown in table 4 . There was, on average, an increase in asthma admissions to adult intensive care units by an average of $4.7 \%$ per year (95\% CI 2.8 to 6.7 ) across the 10-year period.

Table 2 Admissions to critical care units with acute asthma in England and Wales by age and sex

\begin{tabular}{lllr}
\hline & Males & \multicolumn{1}{l}{ Females } \\
& $\mathbf{n}(\%)$ & n (\%) & Total \\
\hline Critical care & $3884(32.5)$ & $8064(67.5)$ & 11948 \\
admissions with acute & & \\
asthma & & \\
Acute asthma admissions by age band & \\
$<15$ & $250(60.1)$ & $166(39.9)$ & 416 \\
$15-19$ & $245(33.1)$ & $495(66.9)$ & 740 \\
$20-24$ & $288(28.4)$ & $726(71.6)$ & 1014 \\
$25-29$ & $286(27.0)$ & $772(73.0)$ & 1058 \\
$30-34$ & $327(26.7)$ & $896(73.3)$ & 1223 \\
$35-39$ & $357(27.9)$ & $921(72.1)$ & 1278 \\
$40-44$ & $392(30.2)$ & $905(69.8)$ & 1297 \\
$45-49$ & $342(28.7)$ & $851(71.3)$ & 1193 \\
$50-54$ & $295(33.8)$ & $577(66.2)$ & 872 \\
$55-59$ & $314(40.1)$ & $469(59.9)$ & 783 \\
$60-64$ & $210(38.8)$ & $331(61.2)$ & 541 \\
$65-69$ & $197(38.0)$ & $322(62.0)$ & 519 \\
$70-74$ & $156(39.1)$ & $243(60.1)$ & 399 \\
$75-79$ & $142(41.3)$ & $202(58.7)$ & 344 \\
$\geq 80$ & $83(30.6)$ & $188(69.4)$ & 271 \\
\hline
\end{tabular}

Data are presented as number of admissions (percentage within age group).
Table 3 Mortality in admissions with acute asthma in adult critical care units in England and Wales, between 2002 and 2011, by age group and sex

\begin{tabular}{|c|c|c|c|c|}
\hline \multirow[b]{2}{*}{ Age group } & \multicolumn{2}{|c|}{ Critical care deaths } & \multicolumn{2}{|c|}{$\begin{array}{l}\text { Acute hospital } \\
\text { deaths* }\end{array}$} \\
\hline & Male & Female & Male & Female \\
\hline$<15$ & $3(1.2)$ & $0(0)$ & $6(2.5)$ & $2(1.2)$ \\
\hline $15-19$ & $7(2.9)$ & $7(1.4)$ & 8 (3.3) & $7(1.4)$ \\
\hline $20-24$ & $6(2.1)$ & $11(1.5)$ & $8(2.8)$ & $13(1.8)$ \\
\hline $25-29$ & $4(1.4)$ & $9(1.2)$ & $4(1.4)$ & $11(1.5)$ \\
\hline $30-34$ & $1(0.3)$ & $11(1.2)$ & $4(1.3)$ & $15(1.7)$ \\
\hline $35-39$ & $8(2.2)$ & $13(1.4)$ & $9(2.6)$ & $19(2.1)$ \\
\hline $40-44$ & $11(2.8)$ & $19(2.1)$ & $15(3.9)$ & 19 (2.2) \\
\hline $45-49$ & $7(2.0)$ & $38(4.5)$ & $11(3.3)$ & $47(5.7)$ \\
\hline $50-54$ & $14(4.7)$ & $38(6.6)$ & $20(7.0)$ & $45(8.0)$ \\
\hline $55-59$ & $24(7.6)$ & $45(9.6)$ & $32(10.5)$ & $55(12.0)$ \\
\hline $60-64$ & $16(7.6)$ & $41(12.4)$ & $23(11.2)$ & $57(17.6)$ \\
\hline $65-69$ & $21(10.7)$ & $39(12.1)$ & $34(17.7)$ & $61(19.3)$ \\
\hline $70-74$ & $15(9.6)$ & 33 (13.6) & 25 (16.2) & $45(19.1)$ \\
\hline $75-79$ & $23(16.2)$ & $34(16.8)$ & $33(23.6)$ & $47(24.1)$ \\
\hline$>80$ & $19(22.9)$ & $39(20.7)$ & 29 (34.9) & 59 (32.2) \\
\hline \multicolumn{5}{|c|}{$\begin{array}{l}\text { Data are presented as number of deaths (\% admissions within sex } \\
\text { and age group). } \\
\text { *Excludes re-admissions to the critical care unit during the } \\
\text { hospital stay. }\end{array}$} \\
\hline
\end{tabular}

\section{DISCUSSION}

This study has demonstrated that acute asthma represents a modest burden of work on critical care units in England and Wales when compared to diseases such as pneumonia $(5.9 \%) .{ }^{12}$ Critical care unit survival rate was greater than $95 \%$. This is an unusually high survival rate for emergency medical admissions to intensive care in the UK (overall survival $77.4 \%$ ). ${ }^{13}$ The reasons behind this are not clear, but are probably a function of asthma, by definition, having some reversibility as part of the disease process and therefore an area to exploit therapeutically. Compared to chronic obstructive pulmonary disease (COPD), adult patients with asthma are less likely to have other comorbidities and therefore a better outcome. ${ }^{14}$ Asthma is also predominantly non-infective. Patients who have sterile inflammatory insults, for example anaphylaxis ${ }^{15}$ and cardiac surgery, ${ }^{16}$ also appear to have survival rates in excess of $90 \%$. This is much higher than those with all-cause sepsis, ${ }^{17}$ which is around $60 \%$ and pneumonia, which is around $50 \% .^{12}$ It is difficult to account for this, other than to say that acute, non-septic inflammatory insults tend to be 'point' insults, rather than the ongoing inflammation of infection. We cannot tease out of our data which episodes of 'acute asthma' had an infective component and which did not.

The sex ratios reflect the previously well-documented sex variation in asthma; prevalence is higher in females and they are more likely to be admitted to and stay longer in hospitals. ${ }^{18}$ Prior to puberty, males predominate. These sex differences are also reflected in other allergic conditions such as anaphylaxis ${ }^{19}$ and atopy in 
general. The causes of this again are not fully established, but may be due to female sex hormone levels, ${ }^{20} \mathrm{a}$ different aetiology of airway hyper-reflexiveness between males and females or differences in immunology between the sexes. ${ }^{21}$

ICNARC data only records those who were ventilated in the first $24 \mathrm{~h}$ after critical care admission. However, it is likely that this accounts for most of those who were invasively ventilated with acute asthma. Rates of ventilation were higher than that reported in Australia ${ }^{22}$ and the USA. ${ }^{23}$ This is likely due to the differing geographical models for what defines critical care. Owing to reduced numbers of critical care beds per capita in the UK compared with the USA, patients in UK critical care units have a much higher illness severity than those in the USA. ${ }^{5}$

In asthma patients, the median length of adult critical care unit stay was less than 2 days. This is a shorter time period to previously published studies in asthma patients in the US healthcare system ${ }^{23}$ and has not reduced when compared to the late $1990 \mathrm{~s}$ in the UK. ${ }^{24}$ Median length of total acute hospital stay in this study population with asthma was 7 days. This is comparable to length of hospital stay for those admitted for asthma in a critical care area in the US system. It also represents a reduction of hospital LOS by around 1 day in the UK when compared with the late 1990s. ${ }^{24}$ Again, this is probably representative of the differing criteria for critical care between the UK and the USA rather than true disease variation or outcome differences. Proportionally fewer patients were ventilated in our study population compared to previous studies. ${ }^{24}$ Identifying the reason for this is not straightforward. During this time, there was a rise in UK critical care bed numbers by $30 \%,{ }^{25}$ which may mean that critical care is offered to a wider group of patients (ie, the less unwell) or it may represent reduced disease severity and improved earlier intervention.

Mortality, both in terms of absolute numbers and percentage, increased with age. This will inevitably be due to the reduced physiological reserve and the increased comorbidities associated with increasing age. We have no information about which patients died due to 'therapeutic failure' and which patients died as a result of withdrawal of care. It is noticeable however, that younger patients who died, had died in the critical care unit and this proportion reduces with increasing age.

Trends in asthma admissions with time in the UK adult critical care units show that the number of admissions is rising. This should be interpreted with caution when using these figures, since the number of critical care beds and all cause admissions included in ICNARC's CMP has increased by $40 \%$ and $130 \%$, respectively across the same period. ${ }^{26}$ The severity of asthma at presentation is also unknown in this dataset, which makes understanding the trends more difficult. Admissions, both to hospital and the critical care unit are not based on static criteria, but on the severity of the asthma, as well as the availability of beds and healthcare culture. This means that the rise in admissions may have resulted from a lower admission threshold, rather than any true increase in numbers of those with severe disease.

Both incidence and prevalence of asthma increased over the 20th century and although recently there have been reports that new diagnoses are beginning to fall, ${ }^{27}$ a recent systematic review found that in most parts of the world prevalence is still increasing, or is at best static. $^{28}$

Rates of admission, ventilation and outcomes for asthma in critical care units differ from country to country (see table 1). This probably reflects region and country specific differences in healthcare systems rather than true disease variation. ${ }^{5}$ Thus, although we can compare our results to previous studies from developed countries, when doing so we should not assume that differences in outcomes are due to differences in care quality. There may be differences in case-mix of patients.

The strengths of this study also lies in the database that it is drawn from. The data produced by ICNARC's CMP database is a large national audit, both in terms of number of participating units and number of patients and is well validated. The model of care in the UK means that there are few critical care units in the private sector that take acute medical emergencies such as acute asthma. Thus the number of missed cases due to this is likely to be small. ICNARC also covers few specialist critical care units. Therefore, there may also be a small number of admissions that are admitted to specialist units such as cardiac and neurointensive care units in specialist hospitals. Again, the number of these is likely to be small. We cannot state with confidence what proportion of general critical care units the ICNARC CMP covers, although it is currently quoted as around $95 \% .^{29}$ The actual coverage of the dataset used for analysis is however lower than this. This is a combination of the number of units that have joined the CMP over the years, the time it takes from starting to collect data to having adequate quality data in the database, and the fact that participation does not always ultimately translate into data of sufficient quality being made available in the database. 
This is the largest study based on number of admissions with asthma admitted to adult critical care units ever undertaken (see table 1). Previous studies have been on smaller number of admissions, or for relatively shorter periods of time. We are likely to see improved epidemiological data for a variety of conditions in critical care with the UK, France, Australia and New Zealand all producing high quality, validated national audits of critical care activity which may be interrogated at the national or local level. Our data confirm the previously published high survival rates in asthma admissions, regardless of region.

The limitations of this study lie in the diagnosis of asthma itself. Asthma is increasingly recognised as the clinical outcome of a number of heterogeneous pathways and discussions over the correct method of diagnosis still exist. $^{30}$ This, added to the crossover in diagnosis between bronchiolitis, COPD, pneumonia in an asthmatic and heart failure, or 'cardiac' asthma make actual assessment of the epidemiology of 'diagnostically correct' asthma difficult. However, this is a limitation in virtually all studies of asthma epidemiology and the frequency of cross over in our study is unlikely to be different to any other. Our needing to work with aggregate data-because of concerns regarding small numbers in some cells and the risks of disclosure-was a further limitation as this limited the analyses that we were able to undertake. We were thus, for example, not in a position to undertake sensitivity analyses to investigate the possibilities of diagnostic coding errors at the extremes of age.

In summary, acute severe asthma represents a modest burden of work for the critical care unit in England and Wales, but with relatively good outcomes compared to other emergency admissions. The demographics follow those of asthma in general, that is, a female preponderance. The proportion of patients requiring invasive ventilation has reduced since the late 1990s. LOS in both critical care units and hospitals as a whole has not decreased since the mid 1990s and is not broadly different to stays in other countries with differing healthcare systems.

Acknowledgements The authors would like to acknowledge Intensive Care National Audit and Research Centre for sharing their data.

Contributors BG collated and analysed the data and wrote and edited the manuscript. KG collated and analysed data and edited the manuscript. MM analysed the data and edited the manuscript. AS conceived the study and wrote and edited the manuscript.

Funding None.

Competing interests $B G$ is partially supported by the National Institute of Health Research (NIHR) Bristol Cardiovascular Biomedical Research Unit. MM is supported by University of Edinburgh through the Edinburgh Health Services Research Unit.

Provenance and peer review Not commissioned; externally peer reviewed.

Data sharing statement No further data is available from the authors. For more information, please contact ICNARC.

Open Access This is an Open Access article distributed in accordance with the Creative Commons Attribution Non Commercial (CC BY-NC 3.0) license, which permits others to distribute, remix, adapt, build upon this work noncommercially, and license their derivative works on different terms, provided the original work is properly cited and the use is non-commercial. See: http:// creativecommons.org/licenses/by-nc/3.0/

\section{REFERENCES}

1. Gupta R, Sheikh A, Strachan DP, et al. Burden of allergic disease in the UK: secondary analyses of national databases. Clin Exp Allergy 2004;34:520-6.

2. Weiss KB, Sullivan SD. The health economics of asthma and rhinitis. I. Assessing the economic impact. J Allergy Clin Immunol 2001;107:3-8.

3. Global Initiative for asthma (GINA). Global Strategy for Asthma Management and Prevention. 2012. http://www.ginasthma.org/ guidelines-gina-report-global-strategy-for-asthma.html

4. Wunsch $\mathrm{H}$, Angus DC, Harrison DA, et al. Variation in critical care services across North America and Western Europe. Crit Care Med 2008;36:2787-93, e1-9.

5. Wunsch H, Angus DC, Harrison DA, et al. Comparison of medical admissions to intensive care units in the United States and United Kingdom. Am J Respir Crit Care Med 2011;183:1666-73.

6. Bratton SL, Newth CJ, Zuppa AF, et al. Critical care for pediatric asthma: wide care variability and challenges for study. Pediatr Crit Care Med 2012;13:407-14.

7. Chiang BL, Hsieh CT, Wang LC, et al. Clinical course and outcome of children with status asthmaticus treated in a pediatric intensive care unit: a 15-year review. J Microbiol Immunol Infect 2009;42:488-93.

8. Hon KL, Tang WS, Leung TF, et al. Outcome of children with life-threatening asthma necessitating pediatric intensive care. Ital J Pediatr 2010;36:47.

9. Triasih R, Duke T, Robertson CF. Outcomes following admission to intensive care for asthma. Arch Dis Child 2011;96:729-34.

10. Harrison DA, Brady AR, Rowan K. Case mix, outcome and length of stay for admissions to adult, general critical care units in England, Wales and Northern Ireland: the Intensive Care National Audit \& Research Centre Case Mix Programme Database. Crit Care 2004;8: R99-111.

11. Armitage P, Berry G. Statistical methods in medical research Oxford, UK: Blackwell Science Ltd, 2002.

12. Woodhead M, Welch CA, Harrison DA, et al. Community-acquired pneumonia on the intensive care unit: secondary analysis of 17,869 cases in the ICNARC Case Mix Programme Database. Crit Care 2006;10(Suppl 2):S1.

13. ICNARC. Annual Summary Statistics. 2010-2011.

14. Wildman MJ, Sanderson CF, Groves J, et al. Survival and quality of life for patients with COPD or asthma admitted to intensive care in a UK multicentre cohort: the COPD and Asthma Outcome Study (CAOS). Thorax 2009;64:128-32.

15. Gibbison B, Sheikh A, McShane P, et al. Anaphylaxis admissions to UK critical care units between 2005 and 2009. Anaesthesia 2012;67:833-9.

16. Care Quality Commission. Heart Surgery in the United Kingdom. 2009. http://heartsurgery.cqc.org.uk/Survival.aspx.

17. Padkin A, Goldfrad C, Brady AR, et al. Epidemiology of severe sepsis occurring in the first $24 \mathrm{~h}$ in intensive care units in England, Wales, and Northern Ireland. Crit Care Med 2003;31:2332-8.

18. Subbarao P, Mandhane PJ, Sears MR. Asthma: epidemiology, etiology and risk factors. Can Med J 2009;181:E181-90.

19. Sheikh A, Alves B. Age, sex, geographical and socio-economic variations in admissions for anaphylaxis: analysis of four years of English hospital data. Clin Exp Allergy 2001;31:1571-6.

20. Tam A, Morrish D, Wadsworth S, et al. The role of female hormones on lung function in chronic lung diseases. BMC Womens Health 2011;11:24.

21. Melgert BN, Ray A, Hylkema $\mathrm{MN}$, et al. Are there reasons why adult asthma is more common in females? Curr Allergy Asthma Rep 2007;7:143-50.

22. Stow PJ, Pilcher D, Wilson J, et al. Improved outcomes from acute severe asthma in Australian intensive care units (1996 2003) Thorax 2007;62:842-7.

23. Pendergraft TB, Stanford $\mathrm{RH}$, Beasley $\mathrm{R}$, et al. Rates and characteristics of intensive care unit admissions and intubations among asthma-related hospitalizations. Ann Allergy Asthma Immunol 2004;93:29-35.

24. Gupta D, Keogh B, Chung KF, et al. Characteristics and outcome for admissions to adult, general critical care units with acute severe asthma: a secondary analysis of the ICNARC Case Mix Programme Database. Crit Care 2004;8:R112-21.

25. UK Department of Health. Critical Care Bed Census (Document KH03A)

26. ICNARC. Annual Summary Statistics. http://www.icnarc.org 
27. Simpson CR, Sheikh A. Trends in the epidemiology of asthma in England: a national study of 333,294 patients. J R Soc Med 2010;103:98-106.

28. Anandan $\mathrm{C}$, Nurmatov $\mathrm{U}$, van Schayck OC, et al. Is the prevalence of asthma declining? Systematic review of epidemiological studies. Allergy 2010;65:152-67.

29. ICNARC. ICNARC CMP—overview. 2013. http://www.icnarc.org

30. Hopkin JM. The diagnosis of asthma, a clinical syndrome. Thorax 2012;67:660-2.

31. Alzeer A, BaHammam A, Masood M, et al. Outcome of patients with severe asthma in the intensive care unit. Ann Saudi Med 2006;26:461-5.
32. Han P, Cole RP. Evolving differences in the presentation of severe asthma requiring intensive care unit admission. Respiration 2004;71:458-62.

33. Khadadah ME, Onadeko BO, Mustafa HT, et al. Clinical features and outcome of management of severe acute asthma (status asthmaticus) in the intensive care unit of a tertiary medical center. Singapore Med J 2000;41:214-17.

34. Pacht ER, Lingo S, St John RC. Clinical features, management, and outcome of patients with severe asthma admitted to the intensive care unit. J Asthma 1995;32:373-7. 